\title{
Hayek's "Scientism" essay: the social aspects of objectivity and the mind
}

\author{
DIOGO LOURENÇO \\ University of Porto
}

\begin{abstract}
In his essay "Scientism and the study of society" Hayek argues that attitudes are central to the moral sciences. Since the natural sciences show that "ordinary experience" often does not reproduce the relations between things in the external world, the understanding of attitudes is possible due to the similarity between the mind of the moral scientist and that of the agent. I argue that Hayek's arguments for the differentiation between the natural sciences and what he calls "ordinary experience" are problematic. I offer an alternative justification by appealing to the manifold goals and social contexts of inquiry. I also elucidate his claim that minds are similar, and how this relates to our understanding of others - both as ordinary agents and as economists. In so doing, I discuss two alternative accounts found in Hayek's work: the first account suggests that understanding is a projection of mental categories from behavioral evidence; the second account-which is found in The sensory order-suggests that understanding is the result of a functional correspondence between structures in the central nervous system.
\end{abstract}

Keywords: Hayek, scientism, Sensory order, propositional attitudes, subjectivism, intersubjectivism

JEL Classification: B31, B41

\section{INTRODUCTION}

F. A. Hayek's (2010a, 2010b, 2010c) three-part "Scientism and the study of society" was part of a wider (aborted) project on what he called The abuse and decline of reason (Caldwell 2010,3). There are so many interpretations of its arguments that Caldwell (2004, app. D) describes it as a Rorschach test. While some see it as a postmodern (Burczak 1994) or hermeneutical exercise (Madison 1989, 1991), others describe it as anti-

Author’s Note: I am grateful to Mário da Graça Moura, to Pedro Nuno Teixeira and to two anonymous referees for their comments and suggestions. This work was possible thanks to the financial support of the Foundation for Science and Technology (FCT) in the form of a PhD grant (SFRH / BD / 71701 / 2010). I also acknowledge the support of CEF-UP. 
modernist and non-hermeneutic (Caldwell 1994); moreover, while some interpret it as almost positivistic (Lawson 1997, ch. 10), others applaud the soundness of some of its ontological commitments (Runde 2001).

Hayek's manner of writing has led to conceptual and exegetical ambiguity, which is the source of this extraordinary number of interpretations. But Hayek's "Scientism" essay is not a barren mismatch of contradictory lines of thought; rather, it is a long piece, rich with innovative reflections on topics ranging from the philosophy of science to psychology, pregnant with fruitful suggestions that the secondary literature tries to bring to light. It is a singular piece in the history of economic and social thought-in Oakley's (1999) words, "a remarkable series of papers" - and of great importance to Hayek's oeuvre. As Caldwell (1998, 224) writes, it "contains all the essential elements of [Hayek's] methodological programme".

Its kaleidoscopic details notwithstanding, the aim and argument of Hayek's essay is clear: the general success of modern natural sciences has led to the emulation of their methods in other fields, often without due consideration for the unique properties of their objects of study. He intends to show why the methods of the natural sciences are inappropriate for social scientific explanation, and the errors to which their adoption in the social or, to adopt his expression, moral sciences leads.

For Hayek, natural scientific explanation begins with the observation that ordinary people classify as similar what turns out to behave differently in similar circumstances, and vice-versa (2010a, 83). In her attempt to objectively explain phenomena, the natural scientist must therefore revise ordinary experience. The moral sciences, by contrast, are concerned with action. Yet, action is related to people's attitudes-i.e., to what they think, believe, desire, etc--hence, unlike the natural scientist, the moral scientist cannot ignore (much less transcend) the subjective attitudes that govern agents' behaviors. But this raises a problem: if ordinary experience is shown by the natural sciences to misrepresent the relations things objectively hold among each other, the moral scientist cannot ascertain agents' attitudes by merely studying a reality external to them. The solution to this predicament is for the moral scientist to tap into what she has in common with the agents she studies-viz., that she and her subjects have minds.

In this article I will evaluate some of Hayek's arguments in his "Scientism" essay and related works. In so doing, I will demonstrate the importance and fruitfulness of this text as a point of departure for 
philosophical reflections on the nature of moral scientific explanation. In particular, I pursue lines of inquiry Hayek initiated but left unexplored and show how some of his most critical insights can be supported by arguments different than his.

The paper has the following structure: in sections 2 and 3 I summarize and discuss Hayek's main argument. In section 4 I argue that Hayek's distinction between ordinary experience and the world-view of science cannot be sustained by his original arguments, but that the distinction itself can be defended by alluding to the social aspects of inquiry. I then turn to his thesis that moral scientific explanation is made possible by the fact that the scientist is similar to the agents she studies. In section 5, I elucidate what this similarity could be, and how it affects the scientist's understanding of agency. I discuss intersubjective understanding further than Hayek did, emphasizing the limited evidence available to ordinary people in understanding others, and noticing that their attributions of attitudes to fellow human beings are not made determinate by such evidence. Finally, in section 6 I discuss insights from Hayek's work The sensory order to argue that the sort of description of mental states that interests the moral scientist involves properties inextricably linked to the context of social interaction; for this reason such descriptions need have no strict relation to the agent's central nervous system. Hopefully these reflections help to better capture the subjectivity that Hayek argues in the "Scientism" essay to be central to moral scientific explanation.

\section{NATURAL AND MORAL SCIENTIFIC EXPLANATION}

According to Hayek, during the Renaissance (2010a, 81) the "ways of thinking" of modern natural science began to "fight their way" against the established, pre-scientific frames of mind. The latter were often anthropomorphic or animistic, and inquiry was mostly limited to the study of ideas, either those of men or God's. Science, he tells us, replaced these ways of thinking with an ambition to "get down to 'objective facts"'.

Although Hayek's account of the natural sciences begins with these diachronic observations, his argument focuses on how the natural sciences emerged from dissatisfaction with the existing explanations of phenomena. He writes that the natural sciences "revise and reconstruct" both the concepts and the very sense qualities that result from "ordinary experience", and replace them with a framework that is "based on consciously established relations between classes of events" (84). Their 
goal is to achieve generality in explanations, which is to say, to recognize "the particular as an instance of a general rule" (82). ${ }^{1}$

When Hayek turns to the moral sciences, he writes that they are "concerned with man's conscious or reflected action" (88-89). ${ }^{2}$ He informs us that it is not the goal of the moral sciences, barring psychology, to explain individual action in detail, but rather, to identify a "sort of order [that] arises as a result of individual action but without being designed by any individual" (103).

Hayek offers a famous example of such an order: the spontaneous development of a path through wilderness (104). Each person trying to get across wishes to follow a route that is safe, fast, and not too tiring. Confronted with virgin bush, the pioneers might have had to think almost each step through. Their behavior left traces of prior human presence: obstacles removed, foliage cut, stones judiciously placed, footprints. The people coming after the pioneers are likely to have seized, consciously or not, the improvements of the pioneers', adding their own traces to those already existing. A few iterations afterwards, all these traces developed into a clear path which any walker traversing the wilderness will identify and follow. No one planned out the path: it is the result of human action but not of design; an unintended consequence of people traversing the wilderness.

In order to explain such unintended orders, Hayek tells us that we must "understand what the acting people mean by their actions" (94-95, italics added). In the example of the path, we could not explain its formation without understanding the plight of the traversers, that is, what they were trying to do in the circumstances they faced. What an agent means by her actions, i.e., what her intentions are, is related to her reasons for acting. ${ }^{3}$ According to Hayek, action is "determined by the

\footnotetext{
1 This goal of arriving at general rules has been interpreted by Runde $(2001,7)$ in an article otherwise sympathetic to Hayek's "Scientism" essay as a concession to a "positivist" view of science as "being about identifying and establishing event-regularities". But a striking aspect of the "Scientism" essay is Hayek's insouciance about matters of terminological detail. Over a short number of paragraphs, he breezily goes from speaking of reclassification of events (2010a, $83)$, to reclassification of objects (84), reclassification of "external stimuli", "phenomena", and reclassification of "sense impressions" (89). We should thus be wary of reading into Hayek any precise notion of event.

${ }^{2}$ For Hayek, not all the sciences that have a social or a human object of study are moral sciences. There are what he calls "natural social sciences" such as certain branches of epidemiology or neurology that could be studied with the methods of the natural sciences (2010a, 88).

3 The relation between intentions and reasons has caveats which I will disregard, see Davidson (2001c, 79) for a discussion.
} 
views and concepts [the agent] possesses [...] [i.e., by] all [the agents] know and believe" (87). If we interpret Hayek's phrase "determined by" as meaning "caused by", as I believe we should (cf. Caldwell 2004, 245; Cowan and Rizzo 1996, 276f), then Hayek's emphasis on epistemic attitudes (such as knowing and believing) should be extended to include other attitudes as well. Indeed, reasons involve more than what an agent knows and believes, they also include attitudes like desires-what Davidson (2001a, 3-4) calls "pro attitudes".

Agents' reasons for acting offer a form of causal explanation of their behavior (Davidson 2001a). When Hayek writes that the moral sciences do not explain action, he could be taken to mean that the moral scientist often need not be particularly thorough or detailed in the determination of reasons. In this vein, Caldwell $(2004,246)$ writes that it is explanation of belief formation that Hayek leaves out of the domain of the moral sciences, and Fleetwood $(1995,47)$ that it is "the question why individual agents perceive the world in the manner they do". In the example of the path, what reasons individual traversers had for crossing the wilderness, what was salient to their perception, or what inferential tendencies they pursued and why, is, in detail, irrelevant. To account for the appearance of the path, all we need to ascertain is that there were people who wanted to cross, that they wished to do so in an efficient manner, and that they had similar judgments regarding which steps to take. This comes from "our general knowledge of how we and other people behave in the kind of situation in which the successive people find themselves who have to seek their way" (2010a, 104).

However, to what level of detail agents' reasons have to be ascertained depends on the purposes of our research and on our questions. If we want to explain not just the appearance of the path but also want to account for its shape, we would have to be more thorough in our understanding of agents' attitudes: were they trying to go as fast as possible, or erring on the side of safety? It would thus be important to know why the pioneers were traversing the wilderness-it would not have been enough to know that they wished to do so. It is thus misleading to say that the moral sciences do not explain action. ${ }^{4}$ Still, even though we can be more

\footnotetext{
${ }_{4}^{4}$ There are passages in the "Scientism" essay (e.g., 2010a, 88-9) where Hayek explicitly refers to explanation of action in the moral sciences. Alternatively, Madison (1989, 66ff) interprets Hayek's "explain" in the narrow sense of explanation "in physical terms", in opposition to interpreting the meaning of agents' doings. Understood this way, Hayek has a verstehen/erklären distinction in mind, and by "explain" he means that an action is subsumed under laws.
} 
or less detailed in our understanding of agents' reasons, when dealing with complex phenomena, as the moral sciences do, the details that must be disregarded by any human mind impose a limit on the strictness of attainable explanations. As Hayek already notices in the "Scientism" essay (106) and later discusses in greater detail (e.g., in Hayek 1955, 1989), only explanations of the principle are possible.

\section{THE LOGIC OF AGENTS' ATTITUDES}

Important logical implications follow from the fact that moral scientific explanations are concerned with action and, therefore, with agents' attitudes. One is that the truth-value of statements in the moral sciences is frequently unrelated to the underlying matters of fact. The sentence "it is raining" may be true or false, but it does not explain Jane's decision to carry an umbrella if the sentence "Jane believes that it is raining" is false. Clearly, to understand individual action the moral scientist must ascertain the truth of statements of the second kind, i.e., statements involving propositional attitudes (to know that, to believe that, to wish that, etc.) Yet, the truth-value of sentences of the form "Jane believes that $p$ " are (logically) independent of the truth-value of $p$. This logical feature is not, however, unique to the moral sciences. Laws of nature, for instance, support counterfactuals: it is true that if the distance between the Earth and the Moon were half of what it is, then the gravitational force attracting the two planets would be four times what it is. It is not because of the actual truth or falsehood of the antecedent or of the consequent that the conditional is true.

Hayek does not, however, explicitly discuss statements involving propositional attitudes. Instead, he emphasizes that the classification of entities in the moral sciences often takes agents' attitudes to be essential. He notices that important moral scientific terms "are abstractions from all the physical attributes of the things in question and their definitions must run entirely in terms of mental attitudes of men towards the things" (2010a, 91, italics in the original). For instance, something is not a tool because it is made of a specific material or because it has a certain shape. Something is a tool due to its intended use (90). In other words, Hayek is

Indeed, Hayek sometimes refers to "full explanation" as entailing lawlike reductions to a physical vocabulary, for instance when arguing that the moral scientist need employ a mental vocabulary until the reduction of the mental to the physical were complete $(2010 \mathrm{a}, 87 ; 1952,190)$, which he argued to be impossible. 
telling us that physical or structural properties of things are neither necessary nor sufficient for their status as objects of action. ${ }^{5}$

It is also the case that the abstraction from the structural properties of things is not distinctive of the moral sciences, a point already partly made by Rudner $(1954,167)$ in an early criticism of Hayek's "Scientism" essay. Many, if not all, the natural sciences employ notions that cannot be defined by the structural properties of their tokens. Take sunburns: a sunburn is definable as a burn caused by exposure to the sun. It is conceivable that two burns are identical down to the atom, yet one be a sunburn and the other not. Yet 'sunburn' is a relevant notion for medical science: they are easily identified in clinical settings, preventable and associated with skin cancer. ${ }^{6}$ What seems distinctive about the moral sciences is, again, the centrality of agents' attitudes.

Hayek's aim in "Scientism" is to show that the world which the agent "builds up" (2010a, 87) is central to the moral sciences; it is this centrality of human attitudes that establishes the fundamental difference between moral and natural sciences. If, on the one hand, the natural sciences need to revise and reconstruct ordinary concepts and experience to develop general explanations, the moral sciences, on the other hand, cannot understand what agents mean by their actions without some understanding or appreciation for the way they view the world. The reclassification that he observes the natural sciences to require is interpreted by Hayek to suggest that agents' world-views need not reproduce the relations that things hold between them objectively (86). ${ }^{7}$

When discussing the subjectivity of agents' world-views, Hayek often reads as if conveying a distinction between appearances-i.e., between our perceptions of the world-and reality-i.e., how the world is revealed by science to actually be. He writes that "ffacts' are different from 'appearances"” (83), he speaks of “'secondary' qualities" (84) and of science's "emancipation" thereof and he mentions "the true nature of the

\footnotetext{
${ }^{5}$ Hayek must not be taken to mean that the structural properties of particular things, such as those of this hammer, are irrelevant for concrete moral scientific practice. That there are usually no necessary or sufficient structural properties defining classes of objects of human action need not mean that there are no structural properties that are typically or conventionally associated with such objects (Hayek 1948, 65-66).

${ }^{6}$ The example of the sunburn, used in a different context, is Davidson's (2001d). ${ }^{7}$ For Hayek, this thesis raises important questions. If true, then "the question why [things] appear to us in that particular way [...] becomes a genuine problem" (2010a, 86). Hayek tries to supply an answer in The sensory order where he elucidates how the order that we call 'mind' can, in principle, arise from the intercourse of the nervous system with its surroundings.
} 
material thing" (93). He also distinguishes between the "objective' properties of things which manifest themselves in their relations to each other, and the properties merely attributed to them by men" (92).

This appearance-reality distinction is not an explicit thesis, but comes across as an undercurrent to his arguments. ${ }^{8}$ Indeed, not only does Hayek employ scare-quotes throughout, but in The sensory order he is explicit in rejecting any such distinction (Hayek 1952, 4). There, he writes that he is not "interested in what a thing 'is' or 'really is' (whatever that may mean), but solely in how a particular object or event differs from other objects or events belonging to the same order or universe of discourse".

In view of this, it is tempting to brush the undercurrent aside and take Hayek to be clumsily conveying a differentiation between two orders or universes of discourse, one organized by the relations between things and the other by those between things and people, and a correlative differentiation between natural science and ordinary experience. Whereas natural scientific endeavors have the conscious goal of elucidating the order formed by the relations between things, ordinary experience is simply the result of the relations between things and people.

\section{ORDINARY EXPERIENCE VERSUS NATURAL SCIENCE}

Indeed, in the "Scientism" essay, Hayek's thesis that agents' world-views need not reproduce the objective relations between things results from his reflections on natural science. He contrasts natural science with ordinary experience, observing that in the natural sciences there is a need to emancipate from the perceptual properties of things and to "revise and reconstruct" (2010a, 81) ordinary experience. He writes that science "begins with the realization that things which appear to us the same do not always behave in the same manner, and that things which appear different to us sometimes prove in all other respects to behave in the same way" (83, italics added). He even goes to the extreme of saying that "we have learned that our senses make things appear to us alike or different which prove to be alike or different in none of their relations between themselves, but only in the way in which they affect our senses" (92, italics added).

\footnotetext{
${ }^{8}$ Madison (1989, 174-176) tries to brush the distinction aside as the result of Hayek's problematic "choice of vocabulary". Fleetwood $(1995$, ch. 4$)$, on the other hand, disagrees that it is merely an undercurrent.
} 
Interpreted literally, however, the possibility of things being different in no other respect than in their effect on the senses defies credulity. ${ }^{9}$ Instead, what I believe Hayek wishes to convey is the observation that two things might have the same structural properties, i.e., the same shape and matter, and yet still be found different by an agent (or vice-versa). For instance, two identical vessels filled with water may be prized differently by an agent, if the water in the one has been blessed by a priest whilst that of the other has not. ${ }^{10}$

It is important to realize that the property of being blessed, although admittedly not a structural property, is still an objective property of the vessel: the truth value of the sentence "the water in the vessel has been blessed" is as independent of anyone's attitudes as that of the sentence "the substance in the vessel is a collection of atoms of hydrogen and oxygen". Moreover, it is noteworthy that there are differences in the relations between each vessel or its contents and other things: not only are there differences in the past, since they are bound to have different causal histories, there are also spatio-temporal differences that affect their relational properties.

What the systematic testing of science shows, however, is that there are differences or effects that may be irrelevant to some science's particular purposes at a particular moment. Relations of similarity are always dependent upon standards, along dimensions, and partaking of degrees. Potassium bitartrate is similar to bicarbonate of soda in that they both conduct electricity when in solution. Yet they differ in that the first can be used to form an acidic solution whereas the second forms an alkaline solution. They are not different or similar tout court. The properties that are salient to people-to scientists and to ordinary folkand the objects individuated by them, adjust to what they are trying to do, to their standpoints and discursive contexts.

For this reason, we must not ignore the social (human) aspects of the several forms of inquiry. Judgments resulting from ordinary experience make distinctions based on the relations between things as much as science does, only such judgments are adjusted to ordinary purposes. They are also subject to revision as such purposes change or new experience accrues, sensory or other (Lindemans 2011, 151ff.). The fact

\footnotetext{
9 Either they would not be more than one thing in the first place, or else "perception" would be an irreducible category of being, which is incompatible with the monistic ontology Hayek $(1952,179)$ defends.

10 I thank an anonymous referee for this example.
} 
that ordinary distinctions are often not suitable for what the natural scientist is trying to achieve in the context of research should not lead to the conclusion that such relational distinctions are "deceptions" (Hayek 2010b, 112).

Hayek also seems to believe that there is something distinctive about the methods of natural science. He writes that natural science revises and replaces not only the concepts formed from ordinary experience but, more importantly, "the very sense qualities which most of us are inclined to regard as the ultimate reality" (2010a, 83, italics added). He goes so far as to write that the second form of reclassification is "the most characteristic procedure of the natural sciences" (84, italics added). Unfortunately, the examples he gives fail to illustrate any replacement of sense qualities, or anything that is characteristic of science.

The most detailed example Hayek gives in the "Scientism" essay is that of a tasteless, scentless white powder, which may prove to be any number of substances, depending on how it reacts in different circumstances. But a distinction among several powders based on how we observe each to react is hardly an example of the replacement of sense qualities. All that happens is that those white powders were all believed to be the same until someone was led to conclude, certainly by way of sense qualities that are classified the same way they used to, that, say, some powders are good for leavening cakes and the others are not, even though they are all white.

Hayek also discusses unobservable entities such as electrons, waves, and fields (84) that do not have any direct effect on the stream of experience to illustrate the emancipation of natural science from perceptible properties. Hayek finds striking today's necessity of speaking of '“visible light' and 'audible sound' when we want to refer to the objects of sense perception" due to the fact that "to the physicist 'light' and 'sound' now are defined in terms of wave motions" (1952, 3). However, the hypostatization of unobservable entities for making sense of the world is a common expedient in ordinary thought, too (Quine 1980, 45). Electrons have no perceptible properties, but neither does the Wrath of God that some have used to explain meteorological catastrophes.

What Hayek's examples show is not a difference between the ways of science and ordinary experience, but the possibility that our immediate sense impressions do not lead us to posit or distinguish entities that, in different circumstances, are associated with other perceptual effects that might make us revise our earlier judgments. The lesson of the examples 
is that the system of classification we employ, the characteristics we find salient, the distinctions we make, and the entities we individuate are subject to revision in view of further evidence from our senses-not that people, much less scientists, should replace "the system of classification which our sense qualities represent" (2010a, 83, italics added). ${ }^{11}$ Moreover, although Hayek often emphasizes that science replaces perceptions with consciously established relations, it is hard to see how conscious classification could be a distinctive characteristic of science. In fact, Hayek $(1952,145)$ later uses it as a defining property of abstract conceptualization in general. ${ }^{12}$

It is curious how little Hayek's account of the method of the natural sciences in the "Scientism" essay seems to characterize science, as opposed to inquiry in general. As Hayek in The sensory order shows, we do not have a static and well-defined picture of the world: people learn, forget, change their minds, etc. Where they notice differences, they separate, where they notice similarities, they associate. When their expectations are borne out, they reinforce them; when expectations are frustrated, people revise them: they change the distinctions they find important to make or to blur, they induce along other paths, and posit new entities. When they are puzzled they may offer bold redefinitions, and may, as science does, hypostatize all sorts of exotic entities in the deepest parts of their ontologies, be they quarks or supernatural activity. ${ }^{13}$

${ }^{11}$ In the second part of the "Scientism" essay, Hayek (1943b, 111-112) justifies "the very loose way in which we have throughout [...] indiscriminately lumped together such concepts as sensation, perceptions, concepts, and ideas" by noticing that "all mental phenomena [...] must be regarded as acts of classification performed by the brain" (italics in the original). No wonder we are hard pressed to find a difference between reclassification of concepts and the replacement of sense qualities that is supposedly "the most characteristic procedure of the natural sciences".

12 An objection might be raised that by 'ordinary experience' Hayek was always only referring to perceptual experience, not to ordinary conceptual thought. There are two problems with this objection. A minor one is that it is clear in the "Scientism" essay that Hayek is interested in more than perceptions, for instance when he writes of the struggle of natural science after its "birth during the Renaissance" (2010a, 81). A major one is that the subjective world-view that matters for the moral sciences is not merely a matter of sense perceptions, but of propositional attitudes.

${ }^{13}$ Later, cf. Hayek (2014d), he explores the competitive processes that lead to the selection of the mental configurations that promote the survival of the organism and species - the experience of the race, as it were (for a discussion, see Lindemans 2011, 155ff). 
Early critics, such as Nagel (1952, 562) and Rudner (1954, 164-67), argued that Hayek's "Scientism" essay failed to identify any methodological difference between the natural and the moral sciences. Popper (1957, ch. 29), at about the same time, also argued for the methodological unity of the sciences. As is well known, Hayek himself moved on to emphasize differences in the degree of complexity of the phenomena studied (cf. 1955, 2014c). Here, I have investigated primarily Hayek's distinction between science and ordinary experience. There are, of course, differences in the purposes, sophistication, contexts, and goals that may justify distinctions between kinds of inquiry, as Rudner (1954, 164) notices. But these are differences in the social aspects of inquiry, not in fundamental method or superior truthfulness of their results.

Indeed, although the arguments Hayek offered for a contrast between science and ordinary experience are unpersuasive once we take the dynamic, social nature of ordinary inquiry into account, the contrast itself can be reinterpreted and upheld from a different, sociological perspective. The differences between the two are not the result of significant differences in method, but social matters of appropriateness to the purposes and contexts of differently motivated people acting in different communities.

However, it is not from the contrast itself but from its supposed implication that ordinary experience is inscrutable to the study of objective reality that Hayek's essay raises the problem of how explanation in the moral sciences is possible at all. He inquires: until the natural sciences are cleansed of "the slightest unexplained residue in man's intellectual processes" (2010a, 87), how can the moral scientist understand an agent, given that the agent's world-view is inscrutable to the objective study of reality external to her? The fact that we can understand and even communicate (92) with others leads Hayek to conclude that people, and thus the moral scientist too, have privileged access to each other's minds: the moral scientist can ascertain attitudes because she is like the agents she studies. An important difference between the natural and the moral sciences is thus that in the moral sciences "our mind must remain not only data to be explained but also data on which the explanation of human action [...] must be based" (87, italics added).

Again, an alternative argument for Hayek's conclusions is available. All that is necessary is to recall what was pointed out in section 3: that there is no logical connection between the truth of a sentence $p$ and the truth of the sentence "agent $\mathrm{X}$ believes that $p$ ". This observation is 
independent of the relation between ordinary experience and natural science. We should thus retain the important contribution of the "Scientism" essay, viz., that the distinction between problems whose (nontrivial) answers involve an appeal to agents' attitudes, and problems whose answers are couched in "physical terms" (2010a, 94).

In the next sections, I elucidate what Hayek believes beings with mind have in common, and venture an argument that explains how these commonalities enable interpersonal understanding of action.

\section{UNDERSTANDING AS PROJECTION OF MENTAL CATEGORIES}

I have shown that, for Hayek, even though agents' world-views may be inscrutable to an objective study of external reality, the moral scientist can nevertheless understand action because she has, and knows that she has, much in common with her subjects.

One thing Hayek makes clear is that he believes that the evidence we use to understand other people is mostly behavioral, i.e., what we observe others "do and say" (2010a, 91). Accordingly, we interpret such evidence "on the analogy of our own mind" (2010b, 139); to use an expression he employs in The facts of the social sciences $(1948,64)$, by "projecting" onto others "the familiar categories of our own thinking" (2010b, 139). In so doing, we go beyond the immediate evidence, "we add" (2010b, 139) or "supplement" $(1948,64)$ "what we perceive with our senses" $(2010 \mathrm{~b}, 139)$. He assures us, however, that this procedure leads to a "satisfactory working explanation of what we observe [...] in the overwhelming number of cases" (2010b, 139).

For example, in The facts Hayek writes that he "shall, from a few observations, be able rapidly to conclude that a man is signaling or hunting, making love to or punishing another person" $(1948,64)$. He believes that "we can derive from the knowledge of our own mind [...] an (at least in principle) exhaustive classification of all the possible forms of intelligible behavior" (67-68, italics in the original). As Hayek can quickly recognize that what someone is doing is a form of hunting or punishing, so the moral scientist is capable of typifying particular behaviors and utilizing them for the organization of experiences, whose ultimate goal is to account for unintended consequences (2010a, 103).

As discussed in section 2, if a classification of action into broad, abstract types is sufficient for some purposes, we often wish to be more detailed in our understanding of agents' reasons for acting. This is true of the moral scientist and of the average person in her everyday 
interactions. We may not recognize a behavior as punishment until we can understand why the punishment is being delivered, or we may not recognize that our friend is signaling if we do not understand what she is trying to convey and why. I think this can be accommodated within Hayek's work if we take his analogy in a broad sense, as a classification of "types of beliefs or attitudes" (2010a, 103, italics added). The analogy would enter our accounts of others in the logic it imposes. I can recognize a form of behavior as murder not because my mind operates like that of the murderer in any strict sense, but because I succeed in identifying the murderer's motivations, i.e., by showing that there is a rational pattern. ${ }^{14}$ As Oakley $(1999,134)$ remarks, "it was apparent to [Hayek] that, as analysts, we are required to attribute to the minds of other agents our own cognitive capacities, characteristics and experiences".

We interact with people by talking with them, observing what they do in public, and then trying to integrate this evidence into coherent frameworks that account for their behavior. Naturally, how we go about integrating the evidence is geared to our purposes. If sometimes we will be satisfied with accounting for someone's concrete reasons for concrete actions, other times we wish to develop complex theories about a specific agent, and make sense in a unified way of our frequent interactionsperhaps we want to identify traits of character.

Upon first meeting another, we do not start from scratch. We have a few promising general starting points that are selected based on immediate evidence and context: people's appearance or accent, our location, moods, etc. (Hayek 2014b, 245). These initial hypotheses are what we can come up with immediately, and probably include much of what Hayek intended to convey with his projections. With further interaction, we revise and supplement these broad, subconsciously selected hypotheses and, perhaps if the agent plays a frequent part in our life's play, we turn them into a custom-made theory about this individual person. As these hypotheses are based on our judgments and projections, our theories are bound to have much of us in them. As Hayek notices, in understanding others we always supplement the available behavioral evidence.

Although Hayek does not elaborate, such supplementation involves choice. Choice in selecting candidate hypotheses and choice in the

${ }^{14}$ See Barry $(1979,26)$, Brodbeck $(1954,145)$ or Nagel $(1952,563)$ for a more critical interpretation of this point. Hayek deals with the objection that his position entails that only a Hitler could understand Hitler in Hayek (2014b, 249250). 
adjustments we make to them. It is a choice because there are alternative hypotheses that we could offer, cumulating in potentially contradictory theories about the agent or action, yet all equally compatible with the evidence available. The explanatory path we follow results from our previous experience as social beings, and bears the signs of our idiosyncrasies and of the social contexts of interaction. There is no expectation that we can uniquely determine our theories with the behavioral evidence available, or reduce the former to the latter: as Quine (1973, 178) and others such as Davidson $(2009,56)$ notice, there are "irreducible leaps" in theory building.

\section{WHY WHAT HAPPENS INSIDE OUR BRAIN MATTERS LITTLE:}

\section{THE QUEST FOR A PRIOR STANDARD OF SIMILARITY}

There is, however, an alternative current in the "Scientism" essay and related works as to what we have in common. According to Hayek, in addition to the analogies that connect our minds, there is a "mental structure" we have in common $(2010 \mathrm{a}, 87)$, and he writes that our concepts (97), "knowledge and beliefs" (92) are similarly structured. Hayek writes, for instance, that "to recognize something as mind is to recognize it as something similar to our own mind, and the possibility of recognizing mind is limited to what is similar to our own mind" (2010b, 139, italics added). There is thus an indication that for Hayek there is a relation of similarity prior to our intersubjective interaction.

This alternative could be expressed by saying that what people have in common involves a "homeomorphism" (2010a, 86) between their mental structures and, possibly, a correspondence between the categories or attitudes in each brain. This interpretation has textual support in The sensory order, in which Hayek expands the view of the mind he offers in the "Scientism" essay that "all mental phenomena [...] must be regarded as acts of classification performed by the brain" (2010b, 111, italics in the original; see also Hayek 1952, 16) in order to, in Caldwell's words, "provide a physiological foundation for subjectivism" $(1994,309)$.

In order to explain cognition, Hayek (1952) introduces two notions, that of a map and of a model. The map is the semi-permanent system of classification of impulses, whereas the model is the transient effect which the present situation is producing on the central nervous system (114-5). Hayek writes that the map arises from an individual's unique causal history with the environment (108-10). Nevertheless, he urges that "the different maps which will thus be formed in different brains will be 
determined by factors which are sufficiently similar to make those maps also similar to each other" (110, italics added). To summarize, what we have in common is a similar central nervous system, resulting from our similar histories, that classifies impulses in a similar way.

In Section 4 I argued that we should be wary of any talk of similarity or associated notions (such as "homeomorphism") if they are introduced independently of context or standard. Since it is not Hayek's purpose in The sensory order to elucidate how we could go about understanding other people, we should not fault him for not giving any standard that is relevant to anyone but the neuro-psychologist. However, in this work, Hayek makes occasional remarks on the nature of communication. He writes that when someone successfully communicates with somebody else, the "symbols" $(1952,135)$ used, when perceived by his interlocutors, will "occupy in their mental order a position analogous to that which they occupy in his own; and which, in consequence, will have for those other persons a meaning similar to that which it possesses for him" (135, italics added; see also ch. 5, section 7; cf. 2010b, 110). Successful communication seems to be explained by there being a corresponding placement of shared events in each mind's order, perhaps made possible by the structural similarity that results from similar histories. Later, Hayek (2014b, 251-252) writes that “'to have meaning' is to have a place in an order which we share with other people".

I wish to highlight two theses from this excursus through The sensory order. First, since Hayek indicates that communication is a consequence of shared events occupying "analogous positions" in the present mental order, this reinforces the point that he must (implicitly) believe that there is some relation of similarity over (subjective) mental positions that is logically prior to, and accounts for, intersubjective agreement. Second, the account and definition of mind found in The sensory order implies that we cannot have differences in the mental order that are not associated with some difference in the central nervous system of the subjects-i.e, it is not possible for two people to be anatomically identical, yet be in different mental states $(1952,110)$.

The picture that emerges is that of a subject, with a mind dependent on interactions with the environment but independent of other minds qua minds, of a relation of similarity over mental states that is solely dependent on the subjects' present anatomy, and of intersubjective agreement as a correspondence between similar subjective mental placements of shared inputs. Hayek would never deny that interaction 
with fellow humans is a crucial part of the causal history with the world leading to present mental states. But the intersubjective, the language game of interaction and interpretation does not, of itself, have any central role in Hayek's account of the mental in The sensory order.

But what could such a prior standard of similarity be? If it is to shed any light on how ordinary people in general (and the moral scientist in particular) use a mental vocabulary in understanding each other's actions, it must reproduce the discrimination made by the manifold public standards that are employed to that effect. More than descriptions of reactions or bodily movements, we wish to account for attitudes, those that form reasons for acting and have propositional content. There are good reasons to believe no such prior standard is possible. First, such a standard would have to be based on neuronal evidence that is not available in the public world where our attributions of attitudes and intersubjective understanding arise. Second, the rules of inference and of normatively charged self-extrapolation employed in the interpretation of others have no equivalent in our understanding of brain structures (Davidson 2001b, 222). Hayek correctly notes that we interpret others on the analogy of our own mind, but no such tendency enters our theorizing about the central nervous system. As we may have two bushes with the exact same overall shape without there being any discernible pattern of similarity or "homeomorphism" at the level of the (topological) placement of individual twigs and branches, our unique brains may yet cumulate in what are, for our theories and judgments based on public evidence and self-projecting tendencies, equal attitudes. ${ }^{15}$

The upshot is that if the descriptions we utilize to identify types of mental phenomena, and, in particular, to individuate and characterize the

\footnotetext{
15 The simile of the bush is Quine's (1964). See Putnam (1975) for a thought experiment in which two brains are exactly equal yet intend different meanings by the same sentence. See also Davidson (2001d) for a discussion and another thought experiment with, for the matter at stake here, similar conclusions. Popper $(1953,395)$ also argues that a "physicalistic causal theory of the human language" is impossible, precisely because the higher functions of human language, viz., the descriptive and argumentative (397), require the attribution of intentionality (401) and other propositional attitudes (402) in interaction in a community of speakers. Popper's article affected Hayek significantly and spurred him to try to meet Popper's challenge by offering a constructive theory of communication in his Within systems and about systems (forthcoming in the volume XIV of his collected works). This work was partly incorporated into Hayek (1955) (cf. Birner 1999, 48; 2014, 64-65, 67; for more on this work, see Birner 1999, sec. 7.1 and Caldwell 2004, 299ff.). According to Birner (2014, 68), Hayek's attempts in Within systems were not successful, as Popper had predicted, "in getting beyond the lowest two functions of communication" (68).
} 
propositional attitudes, are based on the intercourse occurring in the public, intersubjective world outside an individual's head, then there is no expectation that agent's attitudes and intersubjective understanding could, even as a matter of principle, be explained by appealing to what goes on inside her head. It is rather the other way around: if we conclude that two people are of one mind, then we may, perhaps, say that their neuronal order is similar, homeomorphic, etc.

It is important to realize that nothing I have said invalidates the interest of Hayek's neuro-psychological discussion of the mind in The sensory order for the purposes of the psychologist. Moreover, I believe Donald Davidson (e.g., in 2001d) to have successfully argued that the fact that our descriptions and individuations of mental states and events often allude to what is external to the brain does not invalidate the claim that mental states and events are identical with physical states and events - which is fundamental to Hayek's ontology (cf. 1952, 179). It only shows that they need not be identical with states and events in the brain. In other words, our describing mental states and events in ways that suit our intersubjective purposes that are not reducible to neuronal events and states-however complex-does not invalidate the claim that a particular mental event or state is not a complex physical, sometimes neuronal, process. It only shows that the similarities and differences in question are geared to contexts and purposes that are not those of the neuroscientist.

Indeed, what my criticism in this section eliminates is the hope that we will find in The sensory order much that will be of service for the intersubjective notion of mind that is central to the moral sciences. At most, this conclusion indicts Hayek as a moral scientist (not the psychologist) insofar as he is interpreted as finding the similarity that is relevant for understanding action as a homeomorphism of structures individuated without explicit appeal to a social context of public interpretation. ${ }^{16} \mathrm{~A}$ similar conclusion seems to have been reached in a recent conversation between D'Amico and Boettke (2010a, 2010b), Horwitz (2010), and Koppl (2010) on the place of The sensory order in

\footnotetext{
16 More recent work in the Austrian tradition has precisely emphasized the importance of the public, intersubjective world in the fleshing out of subjectivity. These economists, in exploring the radical subjectivist overtones in the tradition, have been influenced by the hermeneutics of Dilthey, Gadamer, Ricoeur, and Schütz, by the work of Michael Polanyi and Weber, as well as by the anthropology of Geertz. For an overview of this literature, see the articles in Boettke (2010), Lavoie (1991) and Prychitko (1995).
} 
Hayek's oeuvre, which bears on the more general question of the contribution of neuroscience to economics. As D'Amico and Boettke (2010a, 375) write "many economists might not find the conversation in neuroscience-no matter how interesting it is for psychology-to improve the explanatory power of economics", even though few would deny that a study of the brain is bound to shed important light on individual choice behavior (Horwitz, 2010 385).

\section{CONCLUSION}

In this article, I explored Hayek's arguments for distinguishing ordinary experience from the world-view of science. I argued that the distinction is sound, but that it cannot be sustained on differences in method or justifiability. I also discussed Hayek's thesis that people are similar by virtue of having minds, and tried to elucidate how we go about understanding each other, concluding that any notion of mind of interest to the student of action cannot ignore the intersubjective world outside agents' central nervous system.

Hayek's works within the decade of the publishing of the "Scientism" essay did not give a central place to the social context of inquiry, or to the social conditions of objectivity and truth (with exceptions, as in Hayek 2010c, 153). In the "Scientism" essay this is best seen in the neglect for the contexts and purposes of inquiry and for the reasonableness of several similarity scales. In The sensory order it is rather seen in Hayek's attempt at describing the development of the individual mind without emphasizing its interaction with other minds qua minds, but only with a normatively amorphous environment. But a mind could hardly develop any notion of objectivity without being a member of a community of fellow creatures. Hayek's arguments thus often rely on an unnecessarily sharp distinction between subjectivism and objectivism, whereas it is more fruitful to think of both as emerging together, in an intersubjective, social world (Davidson 2004). Whatever faults I found are often the result of exploring his suggestions further than he did.

One of the purposes of this article was also to illustrate the fruitfulness of Hayek's "Scientism" essay. Hopefully, it has helped render clearer what the nature of subjectivity is that Hayek identifies as central to the moral sciences in general, and economics in particular; and further, what this entails for the relevant vocabulary for talking about the mind in economics. 


\section{REFERENCES}

Barry, Norman P. 1979. Hayek's social and economic philosophy. London: Macmillan. Birner, Jack. 1999. Making markets. In Economic organization and economic knowledge: essays in honour of Brian J. Loasby, eds. S. C. Dow and P. E. Earl, vol. I. Cheltenham: Edward Elgar, 36-56.

Birner, Jack. 2014. How artificial is intelligence in AI? Arguments for a non-discriminatory Turing test. Paper presented at the International Workshop on Artificial Intelligence and Cognition, Turin.

Boettke, Peter J. (ed.). 2010. Handbook on contemporary Austrian economics. Cheltenham: Edward Elgar.

Brodbeck, May. 1954. On the philosophy of the social sciences. Philosophy of Science, 21 (2): 140-156.

Burczak, Theodore A. 1994. The postmodern moments of F. A. Hayek's economics. Economics and Philosophy, 10 (1): 31-58.

Caldwell, Bruce J. 1994. Hayek's scientific subjectivism. Economics and Philosophy, 10 (2): 305-313.

Caldwell, Bruce J. 1998. F. A. Hayek. In Handbook of economic methodology, eds. John Davids, Wade Hands, and Uskali Mäki. Cheltenham: Edward Elgar, 220-226.

Caldwell, Bruce J. 2004. Hayek's challenge: an intellectual biography of F.A. Hayek. Chicago: University of Chicago Press.

Caldwell, Bruce J. 2010. Introduction. In Studies on the abuse and decline of reason: text and documents, Friedrich A. Hayek, ed. Bruce J. Caldwell. Chicago: University of Chicago Press, 1-45.

Cowan, Robin, and Mario J. Rizzo. 1996. The genetic-causal tradition and modern economic theory. Kyklos, 49 (3): 273-317.

D'Amico, Daniel J., and Peter J. Boettke. 2010a. Making sense out of The sensory order. In The social science of Hayek's 'The sensory order', ed. William N. Butos, vol. 13, Advances in Austrian economics. Bingley: Emerald, 357-381.

D'Amico, Daniel J., and Peter J. Boettke. 2010b. From neuro-Hayekians to subjectivist Hayekians: a reply to Horwitz and Koppl. In The social science of Hayek's 'The sensory order', ed. William. N. Butos, vol 13, Advances in Austrian economics. Bingley: Emerald, 399-403.

Davidson, Donald. 2001a [1963]. Actions, reasons and causes. In Essays on actions and events [2nd ed.], Donald Davidson. New York: Oxford University Press, 12-24.

Davidson, Donald. 2001b [1970]. Mental events. In Essays on actions and events [2nd ed.], Donald Davidson. New York: Oxford University Press, 170-186.

Davidson, Donald. 2001c [1973]. Freedom to act. In Essays on actions and events [2nd ed.], Donald Davidson. New York: Oxford University Press, 59-74.

Davidson, Donald. 2001d [1987]. Knowing one's own mind. In Subjective, intersubjective, objective, Donald Davidson. New York: Oxford University Press, 15-38.

Davidson, Donald. 2004 [1995]. The problem of objectivity. In Problems of rationality, Donald Davidson. New York: Oxford University Press, 3-18.

Davidson, Donald. 2009. Truth and predication. Cambridge (MA): Harvard University Press.

Fleetwood, Steve. 1995. Hayek's political economy: the socio-economics of order. London: Routledge. 
Hayek, Friedrich A. 1948 [1943]. The 'facts' of the social sciences. In Individualism and economic order, Friedrich A. Hayek. Chicago: University of Chicago Press, 57-77.

Hayek, Friedrich A. 1952. The sensory order: an inquiry into the foundations of theoretical psychology. Chicago: University of Chicago Press.

Hayek, Friedrich A. 1989 [1974]. The pretence of knowledge. American Economic Review, 79 (6): 3-7.

Hayek, Friedrich A. 2010a [2010a]. Scientism and the study of society. Part I. In The collected works of F. A. Hayek, ed. Bruce J. Caldwell, vol. 13, Studies on the abuse and decline of reason: text and documents. Chicago: University of Chicago Press, 77-107.

Hayek, Friedrich A. 2010b [1943]. Scientism and the study of society. Part II. In The collected works of F. A. Hayek, ed. Bruce J. Caldwell, vol. 13, Studies on the abuse and decline of reason: text and documents. Chicago: University of Chicago Press, 108141.

Hayek, Friedrich A. 2010c [1944]. Scientism and the study of society. Part III. In The collected works of F. A. Hayek, ed. Bruce J. Caldwell, vol. 13, Studies on the abuse and decline of reason: text and documents. Chicago: University of Chicago Press, 142166.

Hayek, Friedrich A. 2014a [1955]. Degrees of explanation. In The collected works of F. A. Hayek, ed. Bruce J. Caldwell, vol. 15, The market and other orders. Chicago: University of Chicago Press, 195-212.

Hayek, Friedrich A. 2014b [1962]. Rules, perception and intelligibility. In The collected works of F. A. Hayek, ed. Bruce J. Caldwell, vol. 15, The market and other orders. Chicago: University of Chicago Press, 232-255.

Hayek, Friedrich A. 2014c [1964]. The theory of complex phenomena. In The collected works of F. A. Hayek, ed. Bruce J. Caldwell, vol. 15, The market and other orders. Chicago: University of Chicago Press, 257-277.

Hayek, Friedrich A. 2014d [1969]. The primacy of the abstract. In The collected works of F. A. Hayek, ed. Bruce J. Caldwell, vol. 15, The market and other orders. Chicago: University of Chicago Press, 314-327.

Horwitz, Steven. 2010. I am not a "neuro-Hayekian," I'm a subjectivist. In The social science of Hayek's 'The sensory order', ed. William N. Butos, vol. 13, Advances in Austrian economics. Bingley: Emerald, 383-389.

Koppl, Roger. 2010. Confessions of a neuro-Hayekian. In The social science of Hayek's 'The sensory order', ed. William N. Butos, vol. 13, Advances in Austrian economics. Bingley: Emerald, 391-397.

Lavoie, Don (ed.). 1991. Economics and hermeneutics. New York: Routledge.

Lawson, Tony. 1997. Economics and reality. London: Routledge.

Lindemans, Jan W. 2011. Hayek's post-positivist empiricism: experience beyond sensation. In Hayek in mind: Hayek's philosophical psychology, ed. Leslie Marsh, vol. 15, Advances in Austrian economics. Bingley: Emerald, 143-170.

Madison, Gary B. 1989. Hayek and the interpretive turn. Critical Review, 3 (2): 169-185.

Madison, Gary B. 1991. Getting beyond objectivism: the philosophical hermeneutics of Gadamer and Ricoeur. In Economics and hermeneutics, ed. Don Lavoie. New York: Routledge, 32-57.

Nagel, Ernest. 1952. Review of the counter-revolution of science, by F. A. Hayek. The Journal of Philosophy, 49 (17): 560-565.

Oakley, Allen. 1999. The revival of modern Austrian economics: A critical assessment of its subjectivist origins. Cheltenham: Edward Elgar. 
Popper, Karl. 1963 [1953]. Language and the body-mind problem. In Conjectures and refutations - the growth of scientific knowledge, Karl Popper. London: Routledge and Kegan Paul, 395-402.

Popper, Karl. 1957. The poverty of historicism. London: Routledge and Kegan Paul.

Prychitko, David L. (ed.). 1995. Individuals, institutions, interpretations-hermeneutics applied to economics. Aldershot: Averbury Press.

Putnam, Hilary. 1975. The meaning of 'meaning'. In Philosophical papers: volume 2, mind, language and reality. Cambridge: Cambridge University Press, 215-271.

Quine, W. V. O. 1980 [1951]. Two dogmas of empiricism. In From a logical point of view: 9 logico-philosophical essays [2nd ed., revised]. Cambridge (MA): Harvard University Press, 20-46.

Quine, Willard V. O. 1964. Word and object. Cambridge (MA): MIT Press.

Quine, Willard V. O. 1973. The roots of reference. La Salle: Open Court.

Rudner, Richard S. 1954. Philosophy and social science. Philosophy of Science, 21 (2): 164-168.

Runde, Jochen 2001. Bringing social structure back into economics: on critical realism and Hayek's scientism essay. Review of Austrian Economics, 14 (1): 5-24.

Diogo Lourenço is researcher at the Centre for Research in Higher Education Policies and assistant professor at the faculty of economics, University of Porto, Portugal.

Contact e-mail: <dlourenco@fep.up.pt> 